\title{
BMJ Open In-hospital dementia-related deaths following implementation of the national dementia plan: observational study of national death certificates from 1996 to 2016
}

\author{
Miharu Nakanishi, ${ }^{1}$ Syudo Yamasaki, ${ }^{2}$ Atsushi Nishida ${ }^{2}$
}

To cite: Nakanishi M, Yamasaki S, Nishida A. Inhospital dementia-related deaths following implementation of the national dementia plan: observational study of national death certificates from 1996 to 2016. BMJ Open 2018;8:e023172. doi:10.1136/ bmjopen-2018-023172

- Prepublication history and additional material for this paper are available online. To view please visit the journal (http:// dx.doi.org/10.1136/bmjopen2018-023172).

Received 24 March 2018 Revised 20 0ctober 2018 Accepted 9 November 2018
Check for updates

(c) Author(s) (or their employer(s)) 2018. Re-use permitted under CC BY-NC. No commercial re-use. See rights and permissions. Published by BMJ.

${ }^{1}$ Mental Health and Nursing Research Team, Tokyo Metropolitan Institute of Medical Science, Tokyo, Japan

${ }^{2}$ Mental Health Promotion

Project, Tokyo Metropolitan Institute of Medical Science, Tokyo, Japan

Correspondence to Dr Miharu Nakanishi; mnakanishi-tky@umin.ac.jp

\section{ABSTRACT}

Objective To examine changes in places of dementiarelated death following implementation of the national dementia plan and other policy initiatives.

Design Observational study.

Setting Japan between October 1996 and September 2016. Four major changes in health and social care systems were identified: (1) the public long-term care insurance programme (April 2000); (2) community centres as a first access point for older residents (April 2006); (3) medical care system for older people (April 2008) and (4) the national dementia plan (April 2013).

Participants 960423 decedents aged 65 years or older whose primary cause of death was Alzheimer's disease, vascular or other types of dementia or senility.

Main outcome measures Place of death which was classified into 'hospital', 'intermediate geriatric care facility' (rehabilitation facility aimed at home discharge), 'nursing home' or 'own home'.

Results The annual number of deaths at hospital was consistently increased over time from 1996 to 2016 (age-adjusted OR: 6.01; 95\% $\mathrm{Cl} 5.81$ to 6.21 versus home deaths). Controlling for individual characteristics, regional supply of hospital and nursing home beds and other changes in health and social care systems, death from dementia following the national dementia plan was likely to occur in hospital (adjusted OR: 1.21; 95\% Cl 1.18 to 1.24), intermediate geriatric care facility (adjusted OR: $1.53 ; 95 \% \mathrm{Cl} 1.48$ to 1.58 ) or nursing home (adjusted OR: $1.64 ; 95 \% \mathrm{Cl} 1.60$ to 1.69 ) rather than at home. Conclusions As the number of deaths from dementia increased over the decades, in-hospital deaths increased regardless of the national dementia plan. Further strategies should be explored to improve the availability of palliative and end-of-life care at patients' places of residence.

\section{INTRODUCTION}

Dementia is a public health priority with no disease modifying treatments. ${ }^{12}$ Furthermore, dementia is a life-limiting illness and increases the health burden, ${ }^{3}$ and dementia-related death is increasingly common. ${ }^{45}$ Therefore,
Strengths and limitations of this study

- Strengths include being the first study to examine the impact of the national dementia plan on places of dementia-related death in combination with other changes in universal health and social care systems.

- This study took the first crucial step towards the identification of priorities in national dementia strategies and enhanced understanding of appropriate responses to the increase in the number of deaths resulting from dementia.

- Limitations include use of the data from death certificates that did not provide detailed information regarding changes in places of care when close to death.

- The data also lacked information regarding comorbidity.

a palliative care approach should be applied across the disease course in dementia. ${ }^{6}$ In addition, death in hospital could result from the provision of poor-quality care for patients with dementia. ${ }^{7} 8$ Several countries have developed national dementia strategies to help people with dementia to remain in the community as long as possible and die at their usual place of care. ${ }^{910}$ In addition, a number of dementia-related deaths have occurred in hospital. $^{11-14}$

Several factors, such as dementia type, age and cognitive impairment, have been suggested to affect the place of dementia-related death. ${ }^{11-14}$ In addition to these illness-related and individual factors, regional numbers of hospital and nursing home beds that are not specifically allocated to patients with dementia have also been associated with the place of dementia-related death. ${ }^{11} 1516$ Japan also has faced a super-ageing society and a marked increase in the number of people with dementia. The national dementia 
plan (Orange Plan) was launched in April 2013 to address social challenges. ${ }^{9}$ However, little is known about changes in places of dementia-related death following the implementation of the national dementia plan. Empirical evidence involving Japanese individuals could reveal the challenges faced in establishing dementia strategies in an ageing society and enhance understanding of appropriate responses to the increase in the number of deaths resulting from dementia.

The aim of the study was to examine changes in places of dementia-related death following implementation of the national dementia plan in Japan. We hypothesised that the national dementia plan reduced in-hospital deaths from dementia after April 2013.

\section{METHODS \\ Study design}

Data from death certificates, obtained from vital statistics in Japan, were analysed. A detailed description of these data has been reported elsewhere. ${ }^{17}$ Data regarding deaths of Japanese residents aged 65 years or older were extracted from those regarding deaths that occurred in Japan between October 1996 and September 2016.
As dementia care services usually involve universal health and social care systems and dementia-specific services, we examined the associations between places of death and changes in health and social care systems and the national dementia plan. Four major changes in health and social care systems were identified (table 1): (1) the public long-term care insurance (LTCI) programme was introduced in April 2000; (2) general community support centres and community-based care services, including group homes, as well as home-care support clinics were introduced in April 2006; (3) a medical care system for older people was introduced in April 2008 and (4) the national dementia plan was launched in April 2013.

General community support centres serve as a first access point for older residents, including those with dementia, in each local area. ${ }^{9}$ Group homes offer smallscale, homelike accommodation for residents with mild to moderate dementia, and residents with dementia in these homes have shown higher quality of life relative to that of those living at home. ${ }^{18}$ The medical care system for older people includes prefectural (state) health insurers that cover inhabitants aged 75 years or older in the prefecture. Home-care support clinics offer palliative and end-oflife care services to older patients with cancer and other

Table 1 Four changes in health and social care systems in Japan

\section{Period System change}

April 2000 The public long-term care insurance programme was introduced to provide home-care and residential care services to older inhabitants.

- Each local (city) government serves as an insurer providing long-term care insurance for older inhabitants.

- Care managers handle monthly care plans for home-care clients, who usually purchase home-care services from providers other than the care managers.

- Residential care services consist of special nursing homes, intermediate geriatric care facilities and long-term sanatorium care beds.

- Special nursing homes are the only facilities that provide permanent residence under long-term care insurance residential services.

- Intermediate geriatric care facilities provide rehabilitation with the aim of home discharge.

April 2006 General community support centres and community-based care services were introduced into the public longterm care insurance programme.

- General community support centres serve as a first access point for older inhabitants, including those with dementia, in each local area.

- Community-based care service providers handle monthly care plans and offer a package of home-based care services to clients.

- Community-based care services include group homes that accommodate residents with mild to moderate dementia.

Home-care support clinics were introduced into the public healthcare insurance programme.

- Home-care support clinics provide home-based end-of-life care for all diseases, including dementia, in collaboration with home-visit nursing care services.

April 2008 A medical care system for older people was introduced into the public healthcare insurance programme.

- The medical care system for older people established prefectural (state) health insurers to cover inhabitants aged 75 years or older in the prefecture.

April 2013 The national dementia plan (Orange Plan) was launched.

- Initial-phase intensive support teams were established in general community support centres to provide referrals to 'medical centres for dementia' to provide definitive dementia diagnoses and support for people in the early stage of dementia and their families.

- Psychiatric inpatient care involves behaviour management and assistance in the process of home discharge for people with dementia. 
diseases. ${ }^{19}$ The national dementia plan includes initialphase intensive support teams in general community support centres ${ }^{9}$ and provides psychiatric inpatient care, which involves behaviour management and assistance in the process of home discharge for people with dementia.

\section{Patient and public involvement}

Patients and public were not involved in this study.

\section{Data set}

Data regarding the primary cause of death were obtained from death certificates using International Statistical Classification of Diseases and Related Health Problems, Tenth Revision (ICD-10) codes. In Japan, death certificates are completed by a medical doctor within 7 days of death, and the leading cause of death is identified.

\section{Decedents}

Deaths resulting from dementia were identified using ICD-10 codes F00 (dementia in Alzheimer's disease), F01 (vascular dementia), F02 (dementia in other disease), F03 (unspecified dementia) and G30 (Alzheimer's disease). As clinical diagnoses of dementia are under-reported as the main cause of death on death certificates, ${ }^{20}{ }^{21}$ deaths resulting from senility (ICD-10, R54) were also extracted from the mortality data. Senility is included in the following category that requires palliative care: 'Alzheimer's disease, dementia and senility'. ${ }^{13}$

In total, 22308402 deaths were registered in Japan between October 1996 and September 2016, of which 22262049 involved Japanese residents. In addition, 18546639 (83.2\% of 22262049$)$ occurred in people aged 65 years or older. Of the 18546639 decedents who had been resident in Japan and aged 65 years or older, $982809(5.3 \%)$ died of Alzheimer's disease $(n=73531$; $0.4 \%)$, vascular or other dementias $(\mathrm{n}=108427 ; 0.6 \%)$ or senility $(\mathrm{n}=800851 ; 4.3 \%)$. The dementia-related death rate per 100000 inhabitants aged 65 years or older was 9.9 in October 1996 and 26.8 in September 2016.

\section{Measurement}

The dependent variable was place of death, which was classified into the following categories on the death certificates: 'hospital' (medical institution with 20 or more beds), 'clinic' (outpatient clinic or medical institution with 1-19 beds), 'intermediate geriatric care facility' (rehabilitation facility aimed at home discharge), 'nursing home', 'own home' or 'other place, unspecified'. Nursing homes included special nursing homes and fee-based homes for older people. Special nursing homes are the only facilities that provide permanent residence under LTCI residential services. Fee-based homes for older people include housing facilities that are provided in accordance with the Public Aid for the Aged Act, offer additional care and are comparable to assisted living in the USA and extra-care housing in England. Own homes included group homes. Places of death classified as 'other place, unspecified' were excluded from the analysis.
The independent variables were related to the decedents' personal characteristics, regional numbers of hospital and nursing home beds per inhabitant and changes in health and social care systems. Information regarding sex, age at death, marital status and municipality of residence was obtained from death certificate data.

Municipality of residence was associated with the number of available hospital and nursing home beds in the decedent's health region, as follows: available hospital beds per 1000 inhabitants, available special nursing home beds per 1000 inhabitants aged 65 years or older and available fee-based home beds per 1000 inhabitants aged 65 years or older. Regional data were obtained by summing the municipal data for each of the variables (online supplementary table 1 ). Hospital beds were categorised into general acute care, long-term sanatorium care and psychiatric care. The prefectural government allocates healthcare resources based on health regions (called 'the secondary tier of medical care'), which usually include multiple municipalities.

During the study period, the number of municipalities decreased from 3252 to 1741 because of a municipal merger. There were 347 health regions as of 1 October 1996, and the boundaries were revised according to the municipal merger. Therefore, each variable was calculated based on the boundaries of the municipalities and health regions as of the latest survey date following death.

\section{Statistical methods}

The distribution of places of death was calculated per month from October 1996 to September 2016. Yearly age-adjusted ORs of places of death were calculated using multinomial logistic analysis with reference to the first year (October 1996 to September 1997). Multivariate multinomial logistic analysis was also performed using the place of dementia-related death as the dependent variable and the implementation of the national dementia plan as the independent variable. Other decedent and regional characteristics and three changes in health and social care systems were included as covariates. Because data were collected from decedents nested within health regions, a multilevel model was developed using generalised linear and latent mixed models in Stata (Stata, College Station, Texas, USA). ${ }^{22}$ All statistical analyses were performed using Stata SE for Windows, V.15.1 (Stata). The two-tailed significance level was set at. 05 .

\section{RESULTS}

\section{Characteristics of the deceased}

Of the 982809 places of death resulting from Alzheimer's disease, vascular or other types of dementia or senility, 21599 were classified as 'other place, unspecified' and excluded from the analysis. Of the remaining 961210782 and five lacked information regarding marital status and municipality of residence, respectively. The final sample included in the analysis consisted of 960423 decedents 
Table 2 Characteristics of 960423 people who died from Alzheimer's disease, vascular or other types of dementia and senility between October 1996 and September 2016

\begin{tabular}{|c|c|}
\hline \multicolumn{2}{|l|}{ Decedents' characteristics } \\
\hline \multicolumn{2}{|l|}{ Primary cause of death, $\mathrm{n}(\%)$} \\
\hline Alzheimer's disease & $71114(7.4)$ \\
\hline Vascular or other type of dementia & $105425(11.0$ \\
\hline Senility & $783884(81.6)$ \\
\hline Age, year, mean (SD) & $90.9(6.6)$ \\
\hline Sex, male, n (\%) & $252201(26.3$ \\
\hline Nationality, Japanese, n (\%) & $958095(99.8)$ \\
\hline \multicolumn{2}{|l|}{ Marital status, n (\%) } \\
\hline Married & $188578(19.6)$ \\
\hline Divorced & $38658(4.0)$ \\
\hline Widowed & $702171(73.1)$ \\
\hline Single & $31016(3.2)$ \\
\hline \multicolumn{2}{|l|}{ Year of death, n (\%) } \\
\hline Baseline: October 1996 to March 2000 & $87209(9.1)$ \\
\hline $\begin{array}{l}\text { Long-term care insurance: April } 2000 \text { to } \\
\text { March } 2006^{\star}\end{array}$ & $166433(17.3$ \\
\hline $\begin{array}{l}\text { Community general support centre, } \\
\text { community-based care services } \\
\text { and home-care support clinics: April } \\
2006 \text { to March } 2008 \dagger\end{array}$ & $73446(7.6)$ \\
\hline $\begin{array}{l}\text { A medical care system for older people: } \\
\text { April } 2008 \text { to March } 2013 \ddagger\end{array}$ & $293439(30.6)$ \\
\hline $\begin{array}{l}\text { National dementia plan: April } \\
2013 \text { to September } 2016 \S\end{array}$ & $339896(35.4)$ \\
\hline
\end{tabular}

${ }^{*}$ The public long-term care insurance programme was introduced in April 2000.

†General community support centres (first access point for older people) and community-based care services, including group homes, were introduced into the public long-term care insurance programme in April 2006. Home-care support clinics (home-based end-of-life care available for all diseases) were introduced into the public healthcare insurance programme in April 2006.

$\ddagger$ The medical care system for older people (healthcare insurance scheme for people aged 75 years or older) was introduced into the public healthcare insurance programme in April 2008.

$\S$ The national dementia plan (Orange Plan) was launched in April 2013.

(97.7\% of 982809$)$. During the entire study period, $26.3 \%$ of 960423 decedents were men, with a mean age at death of 90.9 years. In addition, $73.1 \%$ of decedents were widowed at death (table 2).

\section{Regional data}

During the study period, the national number of general acute care beds per 1000 inhabitants declined from 10.23 to 7.74. In contrast, the number of long-term sanatorium care beds per inhabitant increased from 0.30 to 2.65, and the number of psychiatric beds per inhabitant remained stable between 2.63 and 2.89. In addition, the number of permanent nursing home beds per 1000 inhabitants aged 65 years or older increased from 12.68 to 15.41 , and the number of fee-based home beds per inhabitant increased from 1.57 to 16.81 .

\section{Outcome data}

During the study period, death in hospital accounted for nearly half ( $\mathrm{n}=434795,45.3 \%)$ of all deaths resulting from Alzheimer's disease, vascular or other types of dementia or senility. In addition, 238429 (24.8\%), 220652 (23.0\%) and $66547(6.9 \%)$ deaths occurred at home, in nursing homes and in intermediate care facilities, respectively.

The number of deaths per month increased gradually from October $1996 \quad(\mathrm{n}=1870)$ to September 2016 $(\mathrm{n}=8994)$, and an annual peak was observed regularly in January for over two decades. The number of deaths in hospital increased from October $1996(\mathrm{n}=584,31.2 \%)$ to September $2016(n=3725,41.4 \%)$. The number of deaths in intermediate geriatric care facilities increased consistently from October $1996(\mathrm{n}=15,0.8 \%)$ to September 2016 $(\mathrm{n}=851,9.5 \%)$, and the number of deaths in nursing homes increased from October $1996(\mathrm{n}=165,8.8 \%)$ to September $2016(\mathrm{n}=3012,33.5 \%)$. In addition, the number of deaths at home was stable between October $1996(\mathrm{n}=1106,59.1 \%)$ and September 2016 ( $\mathrm{n}=1406,15.6 \%$; figure 1).

The age-adjusted ORs versus home deaths per year showed a consistent increase over the two decades in deaths at hospital, nursing home and intermediate geriatric care facility (online supplementary table 2 ).

\section{MAIN RESULTS}

With decedents' and regional characteristics and other changes in health and social care systems controlled for, dementia-related death following the implementation of the national dementia plan was more likely to occur in a hospital, an intermediate geriatric care facility or nursing home relative to the patient's home. Death in hospital was more likely to occur when the cause of death was Alzheimer's disease or another type of dementia, relative to senility and when the decedent was younger relative to older, female relative to male, of a nationality other than Japanese relative to Japanese or divorced or single relative to widowed. In addition, it was more likely to occur after, rather than before, the introduction of the LTCI programme (April 2000), community general support centres, community-based care services and home-care support clinics (April 2006), a medical care system for older people (April 2008) and when the decedents had been residents in regions with a higher, relative to lower, numbers of general acute care beds, psychiatric beds, long-term sanatorium care beds, special nursing home beds or fee-based home beds per inhabitant. Decedents who were married at death were less likely to die in hospital relative to their own homes. With the exception of sex, nationality and the number of long-term sanatorium care beds per inhabitant, these variables were also significantly related to an increased likelihood of death in nursing homes or intermediate geriatric care facilities. Male decedents were more likely, relative to female decedents, to die in hospital or an intermediate geriatric care facility (table 3 ). 


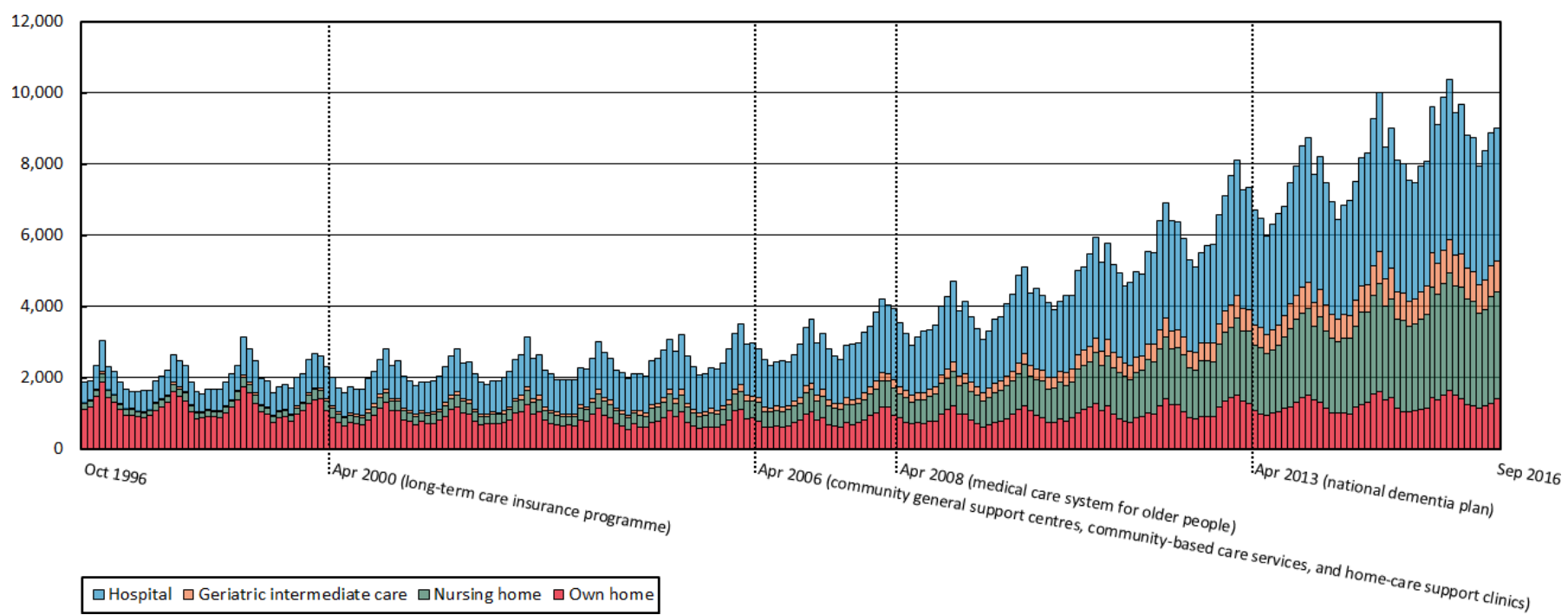

Figure 1 Time trends for the number and distribution of places of death resulting from Alzheimer's disease, vascular or other types of dementia and senility per month. The figure indicates a stacked graph of the number of deaths from Alzheimer's disease, vascular or other types of dementia and senility counted per month. Blue, orange, green and red areas represent death in hospital, an intermediate geriatric care facility, a nursing home and the patient's own home. Intermediate geriatric care facilities provide rehabilitation with the aim of home discharge. Nursing homes include special nursing homes and feebased homes for older people. Special nursing homes are the only facilities that provide permanent residence under long-term care insurance residential services. Fee-based homes for older people are housing facilities provided in accordance with the Public Aid for the Aged Act, offer additional care and are comparable to extra care housing in England. Vertical lines represent the timing of changes in health and social care systems; in April 2000, the public long-term care insurance programme was introduced; in April 2006, community general support centres, community-based care services and home-care support clinics were implemented; in April 2008, a medical care systems for older people was established and in April 2013, the national dementia plan was launched.

\section{DISCUSSION}

Contrary to our hypothesis, death from dementia was more likely to occur in hospital, rather than at patients' homes, even after implementation of the national dementia plan. A yearly age-adjusted likelihood of death in hospital was consistently increased alongside increasing deaths from dementia in Japan over the two decades. An increased likelihood of death in hospital was persistent even controlling for the national dementia plan and other changes in health and social care systems.

The number of deaths resulting from Alzheimer's disease, vascular or other types of dementia or senility increased over two decades. Furthermore, a higher mortality rate was observed in winter, relative to those observed in other seasons, similar to findings in Western countries. ${ }^{23-25}$ Our sample was similar to other countries in demographic characteristics such as age and sex. ${ }^{11}$ However, the proportion of deaths for which Alzheimer's disease or another type of dementia was the primary cause in Japan (1.0\%) was lower relative to those observed in Portugal $(5.5 \%)^{13}$ and Belgium $(9.8 \%){ }^{26}$ The number of deaths resulting from senility was higher relative to those resulting from Alzheimer's disease or vascular or other types of dementia. Moreover, clinical diagnosis of dementia could have been under-reported as a primary cause of death in both Japan and European countries. ${ }^{201}$ Although home-care support clinics address palliative and end-of-life care for home-dwelling people with dementia, home-based end-of-life care services were provided mainly to patients with cancer. ${ }^{19}$ Some health and social care professionals do not recognise dementia as a life-limiting illness. Therefore, national dementia strategies should address the dementia knowledge deficits among health and social care professionals.

In contrast to Western countries, in which most deaths resulting from dementia occurred at nursing homes, hospital was the predominant place of dementia-related death in Japan. ${ }^{11}{ }^{27}$ It should be noted that hospital deaths resulting from Alzheimer's disease, vascular or other types of dementia or senility were less frequent relative to other conditions requiring palliative care, such as malignant neoplasm, in Japan $\left(84.9 \%\right.$ in 2016)..$^{28}$ Therefore, the high prevalence of hospital deaths in Japan stemmed from general end-of-life care practices rather than dementia-specific care. People with advanced dementia are sometimes transferred to hospital from their usual place of care to receive life-sustaining treatment in Japan. For example, special nursing home residents with dementia were typically transferred to hospital (21.5\% of all discharges of residents with dementia), ${ }^{29}$ and tube feeding was introduced for those with no expectation of improved quality of life.$^{30}$ Hospital transfers of actively dying people with advanced dementia is ill advised, as it leads to aggressive medical interventions that are more burdensome to the patient than they are beneficial. ${ }^{31}$ The national dementia plan increased the promotion of advanced care plans concerning decisions to forgo life-sustaining medical treatment at the active dying phase. Nonetheless, there 
Table 3 Multinomial logistic regression analysis of places of death resulting from Alzheimer's disease, vascular or other types of dementia and senility

\begin{tabular}{|c|c|c|c|}
\hline OR, 95\% Cl: reference=own home & Hospital & Nursing home & $\begin{array}{l}\text { Intermediate geriatric } \\
\text { care facility }\end{array}$ \\
\hline \multicolumn{4}{|l|}{ Primary cause of death; reference=senility } \\
\hline Alzheimer's disease & $1.91(1.86 \text { to } 1.95)^{\star}$ & $1.76(1.71 \text { to } 1.81)^{\star}$ & $1.91(1.84 \text { to } 1.99)^{\star}$ \\
\hline Vascular or other type of dementia & $1.84(1.80 \text { to } 1.88)^{*}$ & $1.96(1.92 \text { to } 2.01)^{\star}$ & $2.65(2.58 \text { to } 2.73)^{*}$ \\
\hline Age, year & $0.97(0.96 \text { to } 0.97)^{*}$ & $0.99(0.99 \text { to } 0.99)^{\star}$ & $0.99(0.993 \text { to } 0.996)^{*}$ \\
\hline Sex, male & $1.04(1.02 \text { to } 1.05)^{*}$ & $0.66(0.65 \text { to } 0.67)^{\star}$ & $0.79(0.77 \text { to } 0.81)^{\star}$ \\
\hline Nationality, Japanese & $0.80(0.71 \text { to } 0.89)^{*}$ & 0.99 (0.86 to 1.12$)$ & 1.13 (0.93 to 1.38$)$ \\
\hline \multicolumn{4}{|l|}{ Marital status: reference=widowed } \\
\hline Married & $0.81(0.79 \text { to } 0.82)^{*}$ & $0.62(0.61 \text { to } 0.64)^{\star}$ & $0.70(0.68 \text { to } 0.72)^{*}$ \\
\hline Divorced & $1.42(1.37 \text { to } 1.46)^{*}$ & $2.20(2.12 \text { to } 2.27)^{\star}$ & $1.20(1.14 \text { to } 1.26)^{\star}$ \\
\hline Single & $1.23(1.19 \text { to } 1.28)^{\star}$ & $1.60(1.54 \text { to } 1.66)^{\star}$ & $1.12(1.06 \text { to } 1.18)^{\star}$ \\
\hline \multicolumn{4}{|l|}{ Changes in health and social care systems } \\
\hline Long-term care insurance programme (April 2000) & $1.88(1.82 \text { to } 1.95)^{\star}$ & $2.03(1.94 \text { to } 2.12)^{\star}$ & $3.11(2.91 \text { to } 3.31)^{\star}$ \\
\hline $\begin{array}{l}\text { General community support centres, community-based } \\
\text { care services and home-care support clinics (April 2006) }\end{array}$ & $1.25(1.21 \text { to } 1.29)^{*}$ & $1.57(1.52 \text { to } 1.63)^{\star}$ & $1.70(1.62 \text { to } 1.79)^{*}$ \\
\hline A medical care system for older people (April 2008) & $1.48(1.44 \text { to } 1.52)^{\star}$ & $1.96(1.90 \text { to } 2.03)^{\star}$ & $2.09(2.00 \text { to } 2.18)^{\star}$ \\
\hline National dementia plan (April 2013) & $1.21(1.18 \text { to } 1.24)^{*}$ & $1.64(1.60 \text { to } 1.69)^{\star}$ & $1.53(1.48 \text { to } 1.58)^{*}$ \\
\hline \multicolumn{4}{|l|}{ Regional supply of health and social care services } \\
\hline General acute care beds per 1000 inhabitants & $1.01(1.01 \text { to } 1.02)^{*}$ & $1.02(1.01 \text { to } 1.02)^{*}$ & $1.03(1.02 \text { to } 1.03)^{\star}$ \\
\hline Psychiatric beds per 1000 inhabitants & $1.10(1.10 \text { to } 1.11)^{\star}$ & $1.06(1.05 \text { to } 1.06)^{\star}$ & $1.08(1.07 \text { to } 1.09)^{\star}$ \\
\hline Long-term sanatorium care beds per 1000 inhabitants & $1.05(1.04 \text { to } 1.05)^{*}$ & $1.02(1.01 \text { to } 1.02)^{\star}$ & 1.01 (0.99 to 1.01$)$ \\
\hline $\begin{array}{l}\text { Special nursing home beds per } 1000 \text { inhabitants aged } \\
65 \text { years or older }\end{array}$ & $1.00(1.00 \text { to } 1.01)^{\star}$ & $1.02(1.02 \text { to } 1.02)^{\star}$ & $1.01(1.01 \text { to } 1.01)^{\star}$ \\
\hline $\begin{array}{l}\text { Fee-based home beds per } 1000 \text { inhabitants aged } 65 \text { years } \\
\text { or older }\end{array}$ & $1.02(1.02 \text { to } 1.02)^{*}$ & $1.02(1.02 \text { to } 1.02)^{\star}$ & $1.01(1.00 \text { to } 1.01)^{\star}$ \\
\hline
\end{tabular}

*Significance level $p<0.05$; multilevel multinomial logistic regression analysis, log likelihood=-1101972.80, random effect of health region=0.23 (variance 0.005).

is no advanced care planning legislation in Japan. While the national dementia plan provides initial-phase intensive support teams to support people in the early stages of dementia, advanced care planning is not included in the activities of initial-phase intensive support teams. Even when special nursing homes have residents' preference for end-of-life care documented, there is a risk of hospital transfer when close to death, despite residents' or their relatives' preferences. ${ }^{32}$ Advanced care planning legislation is required to help people who are diagnosed with dementia plan ahead and avoid treatment, such as hospital transfer when close to death, which is more burdensome than it is beneficial.

Death from dementia was more likely to occur in hospital, rather than at patients' homes, even after implementation of the national dementia plan. The plan introduced a 'circulating system of health and social care' via which people with dementia are allocated to a place of care that involves the management of behaviour that is challenging in home-care settings and returns patients to their own homes when this behaviour has improved. The circulating system then provides psychiatric inpatient care involving behaviour management and assistance in the process of home discharge for people with dementia. The large proportion of hospital deaths in our sample could imply that, contrary to expectations, the circulating system failed to help home-dwelling people with dementia to live in the community. Furthermore, inpatients with a primary diagnosis of dementia were usually treated in psychiatric beds $\left(68.6 \%\right.$ as of June 2014), ${ }^{33}$ with long annual durations of hospitalisation and a high in-hospital mortality rate (18.2\% of all discharges). ${ }^{34}$ Patients with dementia in psychiatric hospitals were more likely to die in hospital when the provision of in-home nursing services in their regions of residence was limited. ${ }^{34}$ Therefore, community mental health systems that provide behaviour management should be established to help people with dementia to remain at home and avoid long-term hospital stays in psychiatric beds.

An increased likelihood of death in hospital was also observed after other changes in health and social care systems: the introduction of the LTCI programme, community general support centre and community-based care services, the medical care system for older people and 
home-care support clinics. These policy initiatives aimed to establish home-based health and social care services, to enable older people to stay in their own homes for as long as possible. However, several issues, such as lack of coordination between health and long-term care services and termination of care management when patients are admitted to intermediate geriatric care facilities, special nursing homes or hospitals, have remained. ${ }^{9}$ Notably, the availability of fee-based home beds and psychiatric beds was associated with an increased likelihood of death in hospital or an intermediate geriatric care facility. Although intermediate geriatric care facilities provide intermediate care for older patients who require rehabilitation and aim to be discharged home within 3 months, $44.4 \%$ of discharged patients were admitted to hospital. ${ }^{35}$ The results of the analysis indicated that several transitions could have occurred in end-of-life care, as follows: (1) from a fee-based home to a hospital, (2) from a fee-based home to an intermediate geriatric care facility and (3) from a hospital to an intermediate geriatric care facility. Therefore, the national dementia plan could have failed to address several issues in end-of-life care, against the background of an increasing number of dementia-related deaths. Furthermore, universal health and social care systems should improve care coordination and continuity across various care settings.

There has also been a significant increase in the number of deaths outside hospital. A trend towards an increasing number of deaths in nursing homes was observed during the study period. In addition, the number of fee-based home beds in Japan increased over the two decades for which data were analysed. Greater regional capacity of fee-based home beds was significantly related to the occurrence of dementia-related deaths in nursing homes. This finding is similar to results observed in Finland, where changes to the service structure decreased institutional long-term care facilities and increased the availability of sheltered housing with care. ${ }^{14}$ The changes in Japanese health and social care systems were based on the 'ageing in place' policy and aimed at the establishment of an integrated community care system. ${ }^{36}$ The 'ageing in place' policy included providing older people access to end-of-life care at nursing homes as well as their own homes. These measures directed at end-of-life care may have resulted in increased deaths outside home and inside other facilities. Although group homes were introduced into the LTCI programme and deaths in group homes were included in deaths at patients' own homes, the number of deaths that occurred at patients' own homes generally remained unchanged. In addition, several group homes did not provide end-of-life care to residents. ${ }^{37}$ Furthermore, residents in fee-based homes exhibited more severe healthcare needs relative to those observed in residents of special nursing and group homes. ${ }^{38}$ Therefore, the increase in the number of deaths in nursing home could have resulted from the increase in the availability of fee-based homes as places of residence to address healthcare needs. End-of-life care for persons with dementia may be better than at home in some cases due to the presence of severe challenging behaviours and the prolonged period of disability. However, as mentioned above, nursing home residents with dementia were typically transferred to hospital in Japan. ${ }^{29}$ Capacity of end-of-life care in nursing homes should be improved to increase deaths outside hospital but in usual place of care including nursing homes.

\section{Strengths and weaknesses of this study}

The primary strength of the study lies in the examination of the impact of the national dementia plan on places of dementia-related death in combination with other changes in universal health and social care systems. Other strengths also include the generalisability by use of the national data that are broadly representative of the Japanese population. This study took the first crucial step towards the identification of priorities in national dementia strategies. However, the analyses were subject to limitations associated with mortality data in vital statistics. The data from death certificates did not provide detailed information regarding changes in places of care when close to death. In-hospital deaths of long-stay patients could not be distinguished from hospital transfers of dying residents from their own or nursing homes. The data also lacked information regarding comorbidity. However, as Alzheimer's disease, vascular or other dementias, senility and conditions other than physical illness were recorded as the primary cause of death, a certain level of homogeneity could be assumed in the sample. In addition, dementia might not have been recorded in the death certificates of a number of decedents, such as those whose cause of death was aspiration pneumonia resulting from swallowing difficulty caused by dementia.

\section{Conclusion and policy implications}

Hospital was the predominant place of dementia-related death, regardless of the implementation of the national dementia plan and other policy initiatives. The national dementia plan could have failed to reduce several transitions in end-of-life care against the background of the increasing number of dementia-related deaths. Further strategies should be explored to address (1) advanced care planning legislation, (2) the construction of a community mental health system for behaviour management and (3) care coordination and continuity across various care settings to improve the availability of palliative and end-of-life care at patients' places of residence.

Acknowledgements We thank the Ministry of Health, Labour, and Welfare for its permission and support in the analysis of national death certificate data.

Contributors MN: designed and conceptualised study, data acquisition and curation, data analysis and interpretation, prepared draft manuscript, revised draft manuscript and approved final manuscript for submission. SY: data analysis and interpretation, revised draft manuscript and approved final manuscript for submission. AN: data analysis and interpretation, revised draft manuscript and approved final manuscript for submission.

Funding This research was funded by the JSPS KAKENHI through a Grant-in-Aid for Young Scientists (B) under Grant Number JP15K20796. 
Disclaimer The funding source had no role in the study design; data collection, analysis or interpretation or writing the report.

Competing interests None declared.

Patient consent for publication Not required.

Ethics approval The study was approved by the ethics review board at the Tokyo Metropolitan Institute of Medical Science (15-4), and the procedures were performed in accordance with the Helsinki Declaration of 1975, as revised in 2013.

Provenance and peer review Not commissioned; externally peer reviewed.

Data sharing statement This study was based on the Japanese national death certificate data. The authors do not own these data and hence are not permitted to share them in the original form (only in aggregate form, eg, publications). All death certificate data are owned and maintained by the Ministry of Health, Labour, and Welfare.

Open access This is an open access article distributed in accordance with the Creative Commons Attribution Non Commercial (CC BY-NC 4.0) license, which permits others to distribute, remix, adapt, build upon this work non-commercially, and license their derivative works on different terms, provided the original work is properly cited, appropriate credit is given, any changes made indicated, and the use is non-commercial. See: http://creativecommons.org/licenses/by-nc/4.0/.

\section{REFERENCES}

1. Livingston G, Sommerlad A, Orgeta V, et al. Dementia prevention, intervention, and care. Lancet 2017;390:2673-734

2. World Health Organization and Alzheimer's Disease International. Dementia: a public health priority: World Health Organization, 2012.

3. GBD 2016 Disease and Injury Incidence and Prevalence Collaborators. Global, regional, and national incidence, prevalence, and years lived with disability for 328 diseases and injuries for 195 countries, 1990-2016: a systematic analysis for the Global Burden of Disease Study 2016. Lancet 2017;390:1211-59.

4. GBD 2016 Causes of Death Collaborators. Global, regional, and national age-sex specific mortality for 264 causes of death, 19802016: a systematic analysis for the Global Burden of Disease Study 2016. Lancet 2017;390:1151-210.

5. Alzheimer's Disease International. World Alzheimer report 2016 Improving healthcare for people living with dementia. Coverage, quality and costs now and in the future: Alzheimer's Disease International, 2016.

6. van der Steen JT, Radbruch L, Hertogh CM, et al. White paper defining optimal palliative care in older people with dementia: a Delphi study and recommendations from the European Association for Palliative Care. Palliat Med 2014;28:197-209.

7. Verhofstede R, Smets T, Cohen J, et al. End-of-life care and quality of dying in 23 acute geriatric hospital wards in Flanders, Belgium. J Pain Symptom Manage 2017;53:693-702.

8. Fleming J, Calloway R, Perrels A, et al. Dying comfortably in very old age with or without dementia in different care settings - a representative "older old" population study. BMC Geriatr 2017;17:222.

9. Nakanishi M, Nakashima T. Features of the Japanese national dementia strategy in comparison with international dementia policies: how should a national dementia policy interact with the public healthand social-care systems? Alzheimers Dement 2014;10:468-76.

10. Nakanishi M, Nakashima T, Shindo $Y$, et al. An evaluation of palliative care contents in national dementia strategies in reference to the European Association for Palliative Care white paper. Int Psychogeriatr 2015;27:1551-61.

11. Reyniers T, Deliens L, Pasman HR, et al. International variation in place of death of older people who died from dementia in 14 European and non-European countries. J Am Med Dir Assoc 2015;16:165-71.

12. Black H, Waugh $\mathrm{C}$, Munoz-Arroyo $\mathrm{R}$, et al. Predictors of place of death in South West Scotland 2000-2010: Retrospective cohort study. Palliat Med 2016;30:764-71.

13. Gomes B, Pinheiro MJ, Lopes S, et al. Risk factors for hospital death in conditions needing palliative care: Nationwide population-based death certificate study. Palliat Med 2018;32.

14. Masuchi Y, Jylhä M, Raitanen J, et al. Changes in place of death among people with dementia in Finland between 1998 and 2013: A register study. Alzheimers Dement 2018;10:86-93.

15. Mitchell SL, Teno JM, Miller SC, et al. A national study of the location of death for older persons with dementia. J Am Geriatr Soc 2005;53:299-305.
16. Sleeman KE, Ho YK, Verne J, et al. Reversal of English trend towards hospital death in dementia: a population-based study of place of death and associated individual and regional factors, 2001-2010. BMC Neurol 2014:14:59.

17. Ministry of Health, Labour, and Welfare. Vital statistics survey death form. http://www.mhlw.go.jp/english/database/db-hw/outline/dl/ index-b.pdf (accessed 29 Dec 2017).

18. Nakanishi M, Hirooka K, Morimoto Y, et al. Quality of care for people with dementia and professional caregivers' perspectives regarding palliative care in Japanese community care settings. Int J Geriatr Psychiatry 2017;32:1342-51.

19. Nakanishi M, Niimura J, Nishida A. Factors associated with end-oflife by home-visit nursing-care providers in Japan. Geriatr Gerontol Int 2017;17:991-8.

20. Perera G, Stewart R, Higginson IJ, et al. Reporting of clinically diagnosed dementia on death certificates: retrospective cohort study. Age Ageing 2016;45:667-72.

21. Garcia-Ptacek S, Kåreholt I, Cermakova P, et al. Causes of death according to death certificates in individuals with Dementia: a cohort from the Swedish Dementia Registry. J Am Geriatr Soc 2016;64:e137-e142.

22. Rabe-Hesketh S, Skrondal A. Multilevel and longitudinal modeling using Stata volume II: categorical responses, counts, and survival. 3rd edn: Stata Press, 2012.

23. Laake K, Sverre JM. Winter excess mortality: a comparison between Norway and England plus Wales. Age Ageing 1996;25:343-8.

24. Healy JD. Excess winter mortality in Europe: a cross country analysis identifying key risk factors. J Epidemiol Community Health 2003;57:784-9.

25. Wilkinson $P$, Pattenden $S$, Armstrong $B$, et al. Vulnerability to winter mortality in elderly people in Britain: population based study. BMJ 2004;329:647.

26. Houttekier D, Reyniers T, Deliens L, et al. Dying in hospital with dementia and pneumonia: a nationwide study using death certificate data. Gerontology 2014;60:31-7.

27. Houttekier D, Cohen J, Bilsen J, et al. Place of death of older persons with dementia. A study in five European countries. J Am Geriatr Soc 2010;58:751-6.

28. Ministry of Health, Labour, and Welfare. Vital statistics, 2016: Health, Labour and Welfare Statistics Association, 2018.

29. Nakanishi M, Niimura J, Endo K, et al. Regional supply of nursing home and hospital beds determine discharge destination of nursing home residents in Japan. J Am Med Dir Assoc 2016;17:672.e1-672. e5.

30. Nakanishi M, Hattori K. Percutaneous endoscopic gastrostomy (PEG) tubes are placed in elderly adults in Japan with advanced dementia regardless of expectation of improvement in quality of life. J Nutr Health Aging 2014;18:503-9.

31. Gozalo P, Teno JM, Mitchell SL, et al. End-of-life transitions among nursing home residents with cognitive issues. $N$ Engl $\mathrm{J}$ Med 2011;365:1212-21.

32. Nakanishi M, Miyamoto Y. Documentation of nursing home residents' preferences regarding end-of-life care in Japan: does the documentation serve as an advanced directive in care planning? Eur $J$ Pers Cent Healthc 2015:3:309-17.

33. Ministry of Health, Labour, and Welfare. National patient survey 2014 Health, Labour and Welfare Statistics Association, 2016.

34. Nakanishi M, Niimura J, Yamasaki S, et al. Death of Dementia patients in psychiatric hospitals and regional supply of psychiatric services: study of the national data from 1996 to 2014 in Japan. J Alzheimers Dis 2017;56:817-24.

35. Nakanishi M, Shindo Y, Niimura J. Discharge destination of dementia patients who undergo intermediate care at a facility. J Am Med Dir Assoc 2016;17:92.e1-92.e7.

36. Nakanishi M, Shimizu S, Murai T, et al. "Ageing in place" policy in japan: association between the development of an integrated community care system and the number of nursing home placements under the public long-term care insurance program among municipal governments. Ageing Int 2015;40:248-61.

37. Nakanishi M, Honda T. Processes of decision making and end-oflife care for patients with dementia in group homes in Japan. Arch Gerontol Geriatr 2009;48:296-9.

38. Nakanishi M, Hattori K, Nakashima T, et al. Health care and personal care needs among residents in nursing homes, group homes, and congregate housing in Japan: why does transition occur, and where can the frail elderly establish a permanent residence? J Am Med Dir Assoc 2014;15:76.e1-76.e6. 